\title{
A Numerical Model for Simulation of Thin-Film Water Transport over Solid Fuel Surfaces
}

\author{
KARL MEREDITH, YIBING XIN, and JAAP DE VRIES \\ FM Global, Research Division \\ 1151 Boston Providence Turnpike \\ Norwood, MA 02062 USA
}

\begin{abstract}
A model for simulating water film transport over solid fuel surfaces has been developed. The fundamental film-transport equations for mass continuity, momentum, and energy were formulated. These equations have been implemented in OpenFOAM along with essential source terms for inter-phase transport. The model has been coupled to a gas-phase solver, solid boundary condition, and spray transport model. Initial validation of the model has been performed and good agreement is seen with the Nusselt solution for continuous film flows over inclined surfaces. Comparison of the film model was also made with experimental measurements for film thickness, velocity, and mass flow rate.
\end{abstract}

KEYWORDS: liquid film, two-phase flow, sprinklers, suppression, water transport.

\section{NOMENCLATURE LISTING}

\begin{tabular}{|c|c|c|c|}
\hline$A$ & surface area $\left(\mathrm{m}^{2}\right)$ & $\mu$ & viscosity $(\mathrm{Pa} \cdot \mathrm{s})$ \\
\hline$c_{p}$ & film heat capacity $(\mathrm{J} / \mathrm{kg} \cdot \mathrm{K})$ & $\nabla_{\mathrm{s}}$ & tangential surface gradient operator $\left(\mathrm{m}^{-1}\right)$ \\
\hline$d$ & droplet diameter $(\mathrm{m})$ & $\tau$ & shear stress $\left(\mathrm{N} / \mathrm{m}^{2}\right)$ \\
\hline$D_{A B}$ & binary diffusion coefficient $\left(\mathrm{m}^{2} / \mathrm{s}\right)$ & & density $\left(\mathrm{kg} / \mathrm{m}^{3}\right)$ \\
\hline $\mathbf{F}_{\theta}$ & contact angle force $\left(\mathrm{N} / \mathrm{m}^{2}\right)$ & $\beta$ & \\
\hline g & gravimetric acceleration $\left(\mathrm{m} / \mathrm{s}^{2}\right)$ & $\theta_{e}$ & equilibrium contact angle (rad) \\
\hline$h$ & enthalpy of liquid film $(\mathrm{J} / \mathrm{kg})$ & $\sigma$ & surface tension $(\mathrm{N} / \mathrm{m})$ \\
\hline$h_{\text {conv }}$ & mean heat transfer coefficient $\left(\mathrm{W} / \mathrm{m}^{2} \cdot \mathrm{K}\right)$ & $\Delta_{\mathrm{cl}}$ & width of computational \\
\hline$h_{m}$ & mean mass transfer coefficient $\left(\mathrm{kg} / \mathrm{s} \cdot \mathrm{m}^{2}\right)$ & & cell normal to contact line $(\mathrm{m})$ \\
\hline$L$ & length of flat plate $(\mathrm{m})$ & subs & ripts \\
\hline$M$ & molecular weight $(\mathrm{kg} / \mathrm{kmol})$ & $\infty$ & gas phase, far field \\
\hline$m$ & $\operatorname{mass}(\mathrm{kg})$ & $\rho \delta$ & represents a mass continuity term \\
\hline $\mathbf{n}$ & surface normal vector & & represents a momentum term \\
\hline $\mathrm{Nu}$ & Nusselt number $\left(h_{c o n v, w} \delta / k\right)$ & & \\
\hline$p$ & pressure $(\mathrm{Pa})$ & $\rho \delta h$ & represents an energy term \\
\hline $\operatorname{Pr}$ & Prandtl number & $\delta$ & static pressure related \\
\hline$q$ & convective heat flux $\left(\mathrm{W} / \mathrm{m}^{2}\right)$ & & surface tension related \\
\hline $\operatorname{Re}$ & Reynolds number $(\Gamma / \mu)$ & $a b s$ & absorption \\
\hline$S$ & source term per unit wall area & $c$ & critical film thickness \\
\hline Sc & Schmidt number & $f$ & film \\
\hline$S h$ & Sherwood number & $g$ & gas phase \\
\hline$T$ & temperature $(\mathrm{K})$ & imp & impingement \\
\hline$t$ & surface tangential vector & $l$ & liquid phase \\
\hline $\mathbf{u}$ & tangential film velocity $(\mathrm{m} / \mathrm{s})$ & mar & thermocapillary related \\
\hline $\mathbf{U}$ & mean tangential film velocity $(\mathrm{m} / \mathrm{s})$ & & surface \\
\hline $\mathbf{v}$ & velocity of spray droplet (m) & sep & separation \\
\hline$Y$ & species mass fraction & splash & splashing \\
\hline$z$ & coordinate normal to surface $(\mathrm{m})$ & & tangential \\
\hline Greek & & & vaporization \\
\hline$\delta$ & film thickness (m) & & wall \\
\hline$\beta$ & $\begin{array}{l}\text { empirical coefficient for contact angle } \\
\text { force }\end{array}$ & & \\
\hline$\Gamma$ & mass flow rate per unit width $(\mathrm{kg} / \mathrm{s} \cdot \mathrm{m})$ & & \\
\hline
\end{tabular}




\section{INTRODUCTION}

The overarching goal of sprinkler-based fire suppression modeling is to predict suppression behavior based on underlying physics. Such a modeling effort will vastly reduce the amount of expensive, large-scale testing required for characterization of sprinkler performance and commodity classification, and more importantly, will significantly enhance the understanding of the underlying suppression phenomena. A typical sprinkler-based, rack-storage fire suppression test is shown in Fig. 1.

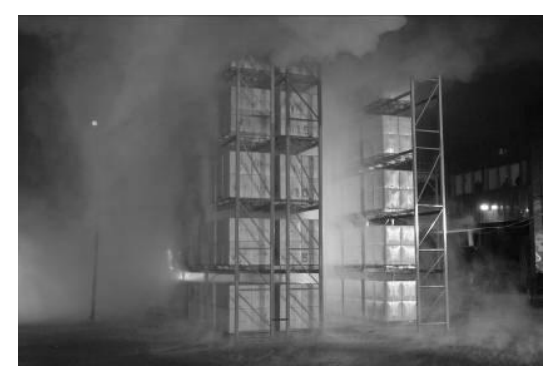

Fig. 1. Typical large-scale rack storage fire suppression test.

A computational fluid dynamics (CFD) model, FireFOAM, has been developed in the OpenFOAM framework for predicting fire growth in rack-storage tests, incorporating physics-based models for turbulence, combustion [1], soot [2], radiation [3], and pyrolysis [4,5]. Two additional model components - sprinkler spray and water-film transport—are needed to move beyond fire growth predictions and focus on suppression modeling. Experimental characterization and initial modeling of sprinkler sprays has been undertaken by Zhou et al. [6]. The goal of the current research is to develop a robust water-film transport model and incorporate this into the general framework established in OpenFOAM for simulating solid-fuel pyrolysis and gas-phase combustion. The combined model will yield a phenomenological-based model for simulating fire growth and suppression.

Work on understanding thin-film flows began in 1910 with the experimental measurements of Hopf [7]. Later, Nusselt [8,9] proposed a theoretical treatment of thin-film flow and heat transfer. An excellent review of the work prior to 1964 has been offered by Fulford et al. [10]. Recent film modeling has focused on volume of fluid (VOF) approaches [11,12] and on applying the lubrication approximation to thin-film flow [13-17]. The VOF models are computationally expensive, while the majority of the lubrication approximation models are not aimed at practical problems, include a limited amount of additional physics, and are overly focused on detailed behavior near the contact line. Excellent experimental work on thin-film flows has been presented as well, such as film separation [18,19] rivulet formation [20,21] and thermocapillary effects [22-24].

\section{MODELING APPROACH}

The scope of the water-film transport model, shown in Fig. 2a, ranges from when the sprinkler spray impinges on the commodity surface to when the water runs off the surface, vaporizes, absorbs into the fuel, or splashes back into the gas phase.

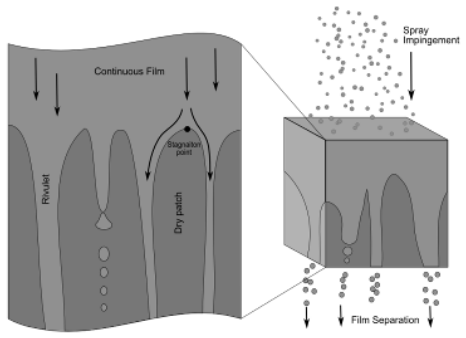

(a)

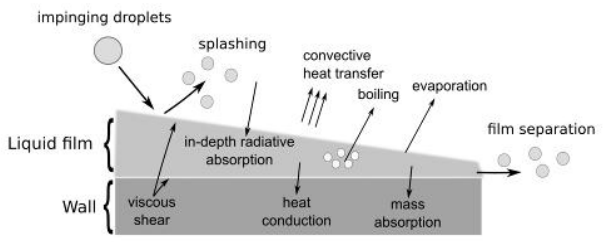

(b)

Fig. 2. The scope of interest for: (a) water-film transport model; (b) interfacial transport processes. 
There are many phenomena that occur during the lifetime of a liquid film in a fire-suppression environment, consisting of partially wetted flow behavior, shown in Fig. 2a, and interfacial transport of mass, momentum, and energy, shown in Fig. 2b. Partially wetted flow behavior entails flow delineated by a contact line separating the dry and wet surfaces, which takes the form of rivulets, dry patches, and isolated wet spots. Interfacial transport concerns interactions between liquid film, gas phase, and solid boundary, and encompasses vaporization, convective/radiative heat transfer, etc.

Due to the thin nature of the liquid-film in sprinkler-based suppression situations (usually less than $1 \mathrm{~mm}$ ), the flow in the direction normal to the surface can be assumed negligible. In addition, the diffusive transport of mass/momentum/energy in the surface-normal direction will dominate the tangential diffusion. In other words, advection can be treated in the wall-tangential direction and diffusion processes in the wallnormal direction. This is known as the thin-film assumption and has been used successfully by a number of authors [26-28]. Tangential diffusion effects may become important along the contact line (e.g. at the edges of rivulets), and this feature can be added in the future as necessary.

The thin-film assumption allows integration of the transport equations in the wall-normal direction to obtain a set of equations for the film height, the wall-tangential components of velocity, and the mean film temperature. This integration results in a two-dimensional flow model. Upon integration, the mean film velocity is defined as

$\mathbf{U}=\frac{1}{\delta} \int_{0}^{\delta} \mathbf{u}(z) \mathrm{d} z$

\section{Mass Continuity}

The mass continuity equation is defined as

$$
\frac{\partial \rho \delta}{\partial t}+\nabla_{s} \cdot[\rho \delta \mathbf{U}]=S_{\rho \delta}
$$

$S_{\rho \delta}$ is the mass source per unit wall area due to impingement, splashing, evaporation, absorption into the solid, and film separation.

$S_{\rho \delta}=S_{\rho \delta, i m p}+S_{\rho \delta, s p l a s h}+S_{\rho \delta, v a p}+S_{\rho \delta, a b s}+S_{\rho \delta, \text { sep }}$

The impingement source $S_{\rho \delta, i m p}$ is defined as the mass accumulation over a surface area for a given amount of time

$S_{\rho \delta, i m p}=\sum_{i} m_{i m p, i} / A \Delta t$

The amount of mass impinging on any given surface is computed via interfacing with the Lagrangian particle tracking in the gas phase.

The source terms for splashing and separation are defined similarly. The model for splashing is taken from Bai [31] and Bai et al. [32]. Separation is simplistically treated by allowing droplets to escape from the film on the underside of surfaces when the film thickness builds up to a critical level.

$S_{\rho \delta, v a p}$ is defined as the mass loss over a surface area due to vaporization of the liquid film. Estimation of this term is closely linked with the energy equation. As such, a detailed discussion of the approach for estimating this term is left for the Energy Transport section. 
$S_{\rho \delta, a b s}$ is the mass absorbed into the solid phase per unit surface area. Because many solid combustibles, corrugated cardboard included, are porous and quite hydrophilic, water absorption into the solid must be accounted for. Empirical input, such as that gathered by de Vries et al. [29], is needed for estimation of this term.

$S_{\rho \delta, \text { sep }}$ represents the mass loss due to the liquid film becoming detached from the surface and re-entering the gas phase as liquid droplets. Film separation will occur at corners and edges of the solid surface.

\section{Momentum Transport}

The momentum equation, integrated over film height, is

$$
\frac{\partial \rho \delta \mathbf{U}}{\partial t}+\nabla_{s} \cdot[\rho \delta \mathbf{U U}]=-\delta \nabla_{\mathrm{s}} p+\mathbf{S}_{\rho \delta \mathrm{U}}
$$

The momentum source terms are split into pressure based (tangential gradients in wall-normal forces) and stress based (forces tangential to wall). These source terms are illustrated in Fig. 3.

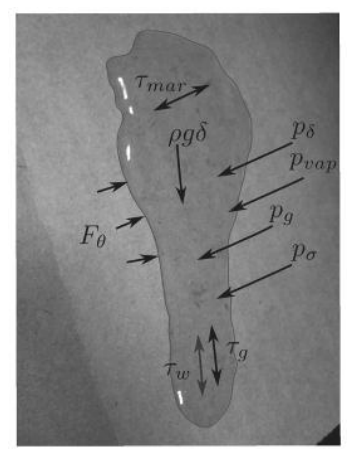

Fig. 3. Source terms present in momentum equation.

\section{Pressure Source Terms}

The pressure term, $p$, comprises forces in the wall-normal direction and consists of spray impingement, splashing, vaporization (also known as the vapor recoil effect), surface tension, hydrostatic pressure head, and local gas-phase pressure. Pressure effects due to absorption of liquid into the solid and film separation of liquid into the gas phase have been neglected due to the very low impact on momentum of these events.

$$
p=p_{\text {imp }}+p_{\text {splash }}+p_{\text {vap }}+p_{\sigma}+p_{\delta}+p_{g}
$$

Impingement pressure, $p_{\text {imp }}$, is the pressure component due to droplet impingement, and is given by

$$
p_{i m p}=\sum_{i} \frac{m_{i m p, i}\left(\mathbf{v}_{i m p, i} \cdot \mathbf{n}\right)}{A \Delta t}
$$

The splashing pressure is defined similarly.

The vapor recoil effect, $p_{v a p}$, is the pressure component due to vaporization of the liquid film, and can be quite significant for high vaporization rates [23]. This term is computed as 
$p_{v a p}=\frac{\rho_{v} u_{v a p}^{2}}{2}=\frac{\left(\dot{m}_{v a p}\right)^{2}}{2 \rho_{v}}$

where $u_{v a p}$ is the surface-normal velocity of the vaporizing gases, $\dot{m}_{v a p}$ is the vaporization flux off the liquid film, and $\rho_{v}$ is the gas phase density. If vaporization is occurring in the off-normal direction (e.g. at the edge of a rivulet), then a corresponding tangential force term would need to be added to the momentum equation as well.

Capillary pressure, $p_{\sigma}$, is the pressure component due to surface tension based on the curvature of the film surface. Using the Laplacian of film thickness to estimate the curvature, the term for the pressure contribution of surface tension is given as

$p_{\sigma}=-\sigma \nabla_{s}^{2} \delta$

This assumption is valid only for surfaces with slight curvature. The curvature of the surface of a thin film should be small everywhere except in regions near the contact line, and especially around stagnation points in the flow. Because of this, a correction factor can be added to the capillary pressure term to account for inadequacies of this assumption.

Hydrostatic pressure, $p_{\delta}$, is the pressure component due to hydrostatic pressure head, and is given by

$p_{\delta}=-\rho(\mathbf{n} \cdot \mathbf{g}) \delta$

This pressure term is eliminated for vertical surfaces $(\mathbf{n} \cdot \mathbf{g}=0)$. Thus, the static pressure head term only influences film spread on horizontal or partially inclined surfaces.

Local gas-phase pressure, $p_{g}$, is the pressure existing in the gas phase just next to the liquid film. This value is taken directly from the gas-phase CFD calculation. For suppression simulations, the influence of $p_{g}$ should be quite weak.

Additional Momentum Source Terms, $\mathbf{S}_{\rho \varsigma \mathrm{U}}$

$\mathbf{S}_{\rho \zeta \mathrm{U}}$ includes the viscous shear stress, thermocapillary stress, gravity body force, and contact-angle force. The momentum sources per unit wall area due to impingement, splashing, vaporization, and film separation into the gas phase are also accounted for.

$\mathbf{S}_{\rho \delta \mathrm{U}}=\boldsymbol{\tau}_{g}-\boldsymbol{\tau}_{w}+\boldsymbol{\tau}_{m a r}+\rho \mathbf{g}_{t} \delta+\mathbf{F}_{\theta}+\mathbf{S}_{\rho \delta \mathrm{U}, \text { imp }}+\mathbf{S}_{\rho \delta \mathrm{U}, \text { splash }}+\mathbf{S}_{\rho \delta \mathrm{U}, \text { sep }}$

The tangential momentum effect due to absorption of liquid into the solid has been neglected because mass absorption is assumed to occur in the surface-normal direction only. In addition, tangential effects of vaporization into the gas phase have been neglected but may need to be accounted for in the future, especially at the edge of the film near the contact line.

The shear stress terms, $\boldsymbol{\tau}_{g}$ and $\boldsymbol{\tau}_{w}$, represent the shear at the film-gas interface and the film-wall interface respectively. $\boldsymbol{\tau}_{g}$ is defined from the gas-phase boundary model. In most fire suppression cases, $\boldsymbol{\tau}_{g}<<\boldsymbol{\tau}_{w}$ because gas-phase velocities for buoyancy-driven flames are typically very low.

The film wall stress term, $\boldsymbol{\tau}_{w}$, is modeled based on an assumed quadratic velocity profile in the wallnormal direction. Experimental data confirm that the quadratic velocity profile assumption remains valid for laminar and wavy laminar film flows [24]. A film can exhibit wavy behavior without necessarily being 
turbulent, and is not fully turbulent until $R e_{f}=\Gamma / \mu>900$ [10], which corresponds to a sprinkler flux of approximately $200 \mathrm{~L} / \mathrm{min} \cdot \mathrm{m}^{2}$. This is well above the range of interest for suppression calculations. Taking the quadratic velocity profile assumption, the shear stress at the wall is found as

$$
\boldsymbol{\tau}_{w}=-\mu \frac{3 \mathbf{U}}{\delta}
$$

The thermocapillary stress term, $\boldsymbol{\tau}_{\text {mar }}$, accounts for the Marangoni effect, or the force induced on the film surface due to surface tension gradients. Temperature gradients on the surface will give rise to surface tension variations, with the surface tension of water being inversely proportional to temperature. The thermocapillary stress tends to drive the fluid from low surface tension regions to regions of high surface tension, or in other words from hot regions to cold regions. This term can become quite pronounced at very high heat fluxes to the liquid film [23,30-35] and contributes to the formation of rivulets and dry spots on the fuel surface. The thermocapillary stress term is implemented as

$\tau_{\text {mar }}=-\nabla_{s} \sigma$

The gravity body force term is represented by $\rho \mathbf{g}_{t} \delta$ where $\mathbf{g}_{t}$ denotes the gravity components tangential to the wall. This term is zero for horizontal surfaces, and is the main driving force for flow over vertical and inclined surfaces.

The contact-angle force term, $\mathbf{F}_{\theta}$, acts along the contact line delineating the separation of wet and dry regions of the flow. This surface-tangential force limits the film from spreading, and is a major cause of partially wetted flow behavior such as rivulets, dry spots, and film rupture. For a given contact angle a film will exhibit a minimum or critical film thickness, $\delta_{c}$. Below this thickness, the film will not be able to flood the surface but will be balanced by the contact angle force. The critical film thickness can be found empirically or estimated from an analytical expression, such as that in Ref. [36]. The contact-angle force is therefore defined as

$$
\mathbf{F}_{\theta}=\beta \frac{\sigma\left(1-\cos \theta_{e}\right)}{\Delta_{c l}} \mathbf{n}_{c l}
$$

where $\theta_{e}$ is the contact angle, $\Delta_{c l}$ represents the width of the computational cell in the direction normal to the contact line, and $\mathbf{n}_{c l}$ denotes the direction normal to the contact line. The parameter $\beta$ is an empirical constant that allows for adjustment of the contact angle force to better model real-world surfaces. For certain porous materials, such as corrugated cardboard, once the surface has been 'wetted' it is very difficult to return to the 'dry' state, even when $\delta<\delta_{c}$. To account for this hysteresis, a phenomenological model is introduced that specifies that a previously wetted film region must reach a value of $\delta \cong 0$ in order to be considered dry again. The contact force equation represents a rather simplistic view of the contact-line behavior. A correction factor, obtained from experimental data for the critical transition from rivulet to flooded flow, may need to be applied in order to simulate realistic flows.

The momentum source term $\mathbf{S}_{\rho \delta \mathrm{U}, \text { imp }}$ captures the wall-tangential momentum derived from the incoming droplets, represented as

$\mathbf{S}_{\rho \delta \mathrm{U}, i m p}=\frac{\sum_{i} m_{i m p, i} \mathbf{v}_{i m p, t, i}}{A \Delta t}$ 
The splashing and separation source terms are defined in a likewise manner.

\section{ENERGY TRANSPORT}

The enthalpy form of the film energy transport equation is represented as

$\frac{\partial \rho \delta h}{\partial t}+\nabla_{s} \cdot[\rho \delta \mathbf{U} h]=S_{\rho \delta h}$

where the film is represented by a mean enthalpy $h$ evaluated at a mean film temperature $T_{f}$. The energy source term, $S_{\rho \delta h}$, is expanded as

$S_{\rho s h}=\dot{q}_{g}^{\prime \prime}+\dot{q}_{w}^{\prime \prime}+S_{\rho s h, v a p}+S_{\rho s h, r a d}+S_{\rho s h, i m p}+S_{\rho s h, s p l a s h}+S_{\rho \delta h, s e p}+S_{\rho s h, a b s}$

The nomenclature used for the energy equation is depicted in Fig. 4.

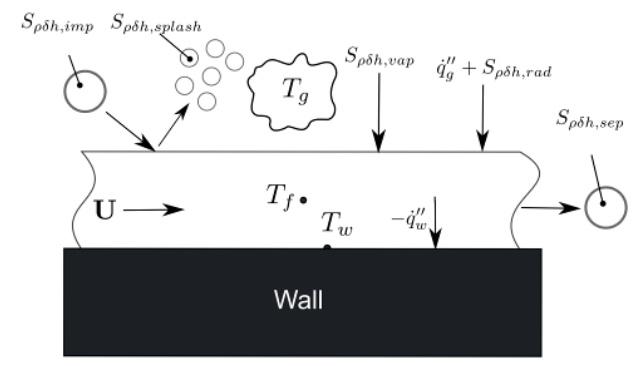

Fig. 4. Film energy equation source terms and nomenclature.

Film-to-Wall Convective Heat Transfer

The convective heat flux to the wall can be represented as

$\dot{q}_{w}^{\prime \prime}=h_{c o n v, w}\left(T_{f}-T_{w}\right)$

The average heat transfer coefficient, $h_{c o n v, w}$, for the solid-liquid interface of a thin film has been shown empirically by Al Khalil et al. [37] to be well characterized by

$\overline{N u}_{f}=\frac{h_{c o n v, w} \delta}{k}=3.20+0.000237 R e_{f}$

where $R e_{f}$ is defined as $\Gamma / \mu$.

Gas Phase-to-Film Convective Heat Transfer

The convective heat transfer from the gas phase to the film can be simplistically represented as

$q_{g}^{\prime \prime}=h_{\text {conv }, g}\left(T_{g}-T_{s}\right)$

For flow over a flat plate, the convective heat transfer coefficient, $h_{c o n v, g}$, has been shown to be correlated with the average Nusselt number defined as [38,39] 
$\overline{N u}_{L}=\left\{\begin{array}{llc}\frac{h_{\text {conv }, g} L}{k}=0.664 \operatorname{Re}_{L}^{1 / 2} \operatorname{Pr}^{1 / 3} & \operatorname{Re}_{L}<5 \times 10^{5} & \operatorname{Pr} \geq 0.6 \\ \frac{h_{\text {conv }, g} L}{k}=0.037 \operatorname{Re}_{L}^{4 / 5} \operatorname{Pr}^{1 / 3} & \operatorname{Re}_{L} \geq 5 \times 10^{5} & 0.6 \leq \operatorname{Pr} \leq 60\end{array}\right.$

where $L$ and $R e_{L}=u_{\infty} L / v$ are based on a user-specified length scale representing the surface and the Prandtl number is defined as $\operatorname{Pr}=\rho c_{p} v / k$. The Reynolds number is based on the relative gas-phase velocity magnitude, or $\left|\mathbf{u}_{\infty}-\mathbf{u}_{\text {film }}\right|$, where $\mathbf{u}_{\infty}$ is the gas-phase velocity next to the film surface and $\mathbf{u}_{\text {film }}=3 / 2 \mathbf{U}$ is the surface velocity of the film. Special consideration may be needed for instances when the gas flow is perpendicular to the water flow.

\section{Vaporization Source Term}

The vaporization energy source term is expressed as

$S_{\rho \delta h, v a p}=-S_{\rho \delta, v a p} h_{v a p}$

where $S_{\rho \delta, v a p}$ represents the vaporization rate and $h_{v a p}$ represents the heat of vaporization.

For vaporization below the boiling point, the mass flux of vaporization at the surface is expressed as

$S_{\rho \delta, v a p}=\frac{-\rho_{g} h_{m}\left(Y_{s}-Y_{\infty}\right)}{1-Y_{s}}$

$Y_{s}$ represents the equilibrium vapor fraction of water at the interface and $Y_{\infty}$ represents the ambient vapor fraction of the vaporizing species.

As an initial approximation, an estimate for the mass transfer coefficient can be obtained from using a Chilton-Colburn analogy with Eq. 22 to replace $\overline{N u}_{L}$ and $\operatorname{Pr}$ with $\overline{S h}_{L}$ and $S c[38,39]$.

$\overline{S h}_{L}=\left\{\begin{array}{llc}\frac{h_{m_{L}} L}{D_{A B}}=0.664 R e_{L}^{1 / 2} S c^{1 / 3} & R e<5 \times 10^{5} & S c \geq 0.6 \\ \frac{h_{m_{L}} L}{D_{A B}}=0.037 R e_{L}^{4 / 5} S c^{1 / 3} & R e \geq 5 \times 10^{5} & 0.6 \leq S c \leq 3000\end{array}\right.$

where again, $L$ and $\operatorname{Re}_{L}=u_{\infty} L / v$ are based on a user-specified length scale representing the surface and $S c=v / D_{A B}$. The Reynolds number is again based on the relative gas-phase velocity, or $\left|u_{\infty}-u_{\text {film }}\right|$.

For vaporization at the boiling temperature, the vaporization rate, $S_{\rho \delta \text {,vap }}$, is no longer a function of the surface concentration gradient and is no longer influenced by boundary layer flow. Rather, for boiling conditions the vaporization rate is based on a simple energy balance necessary to maintaining the temperature at the boiling point.

$S_{\rho \delta, v a p}=\frac{1}{h_{v a p}}\left[S_{\rho \delta h, r a d}+\left(\dot{q}_{g}^{\prime \prime}+\dot{q}_{w}^{\prime \prime}\right)\right]$ 
Additional Source Terms

The energy derived from impinging spray droplets is calculated as

$S_{\rho \delta h, i m p}=\frac{\sum_{i} m_{i m p, i} h_{i m p, i}}{A \Delta t}$

where $m_{i m p, i}$ is the mass and $h_{i m p, i}$ is the enthalpy of the $i^{\text {th }}$ impinging droplet. $A$ and $\Delta t$ are the surface area and time interval over which the impingement source term is averaged. The energy source terms for splashing and separation are defined likewise.

The energy source term associated with mass absorption from a liquid film into a solid wall is

$S_{\rho s h, a b s}=-S_{\rho \delta, a b s} h_{a b s}$

where $S_{\rho \delta, a b s}$ is the mass absorption rate and $h_{a b s}$ is the enthalpy of the absorbed liquid.

$S_{\rho \delta h, r a d}$ represents the radiative absorption deposited in the liquid layer and is obtained from the gas-phase calculation. Currently, as an approximation, all incident radiation is absorbed by the liquid film. Transmission, reflection, and emission are neglected.

\section{MODEL IMPLEMENTATION IN OPENFOAM}

The transport equations for the water-film model and the majority of the source terms have been implemented in OpenFOAM. The film model is solved on a 2-D surface mesh that is discretized in both directions tangential to the surface, but is only one cell thick in the direction normal to the surface. The surface mesh is extruded from the boundary mesh of the larger, gas-phase domain. This approach simplifies the implementation by separating the gas-phase physics from the water transport physics and minimizes communication overhead between the two meshes.

The system of film equations is solved in a segregated fashion. Each equation is currently solved via a Gauss Siedel smooth solver with a diagonal incomplete-LU (asymmetric) (DILU) preconditioner, although the model can also use the other solvers available such as the preconditioned (bi-)conjugate gradient (PBCG) solver or the generalized geometric-algebraic multi-grid (GAMG) solver. Time discretization is performed via a backwards Euler method. The convective terms in the transport equations are solved via a Gauss upwind scheme, gradient terms via a Gauss linear scheme, and diffusive terms via a Gauss linear uncorrected scheme. Convergence criteria were typically set to an absolute tolerance of $1 \times 10^{-10}$ for most equations.

\section{VALIDATION}

\section{Nusselt Solution}

The Nusselt solution [8,9] provides an excellent verification case for the wall-film transport model. For steady-state laminar flow over an inclined flat surface, the tangential velocity downstream of the acceleration zone can be expressed as a quadratic function of distance from the surface through the film thickness. The mean velocity can be found by integrating the velocity profile and the resulting expression can be written in terms of the film Reynolds number, $R e_{f}=\Gamma / \mu$ where $\Gamma=\rho \delta \mathbf{U}$, for both velocity and film thickness.

$U=\left(\frac{v g \sin \theta_{i n c}}{3}\right)^{1 / 3} \operatorname{Re}_{f}^{2 / 3}$ 
$\delta=\left(\frac{3 v^{2}}{g \sin \theta_{i n c}}\right)^{1 / 3} R e_{f}^{1 / 3}$

where $g$ is the value of gravimetric acceleration, $v$ is the kinematic viscosity of the film liquid, and $\theta_{i n c}$ is the inclination angle of the surface.

The wall-film transport model was used to simulate continuous film flow over a flat surface for two inclination angles $\left(5^{\circ}\right.$ and $\left.90^{\circ}\right)$ at a temperature of $298 \mathrm{~K}$. Results of the film model over a wide range of $R e$ are shown in Fig. 5. The predictions for $\delta$ and $U$ compare very favorably with the Nusselt solution and with the experimental data of de Vries et al. [40].

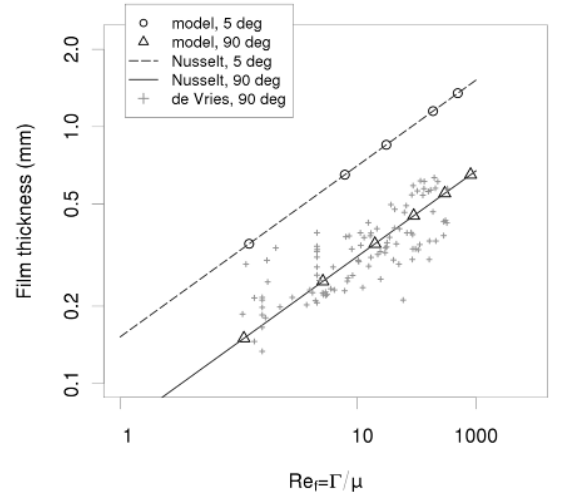

(a)

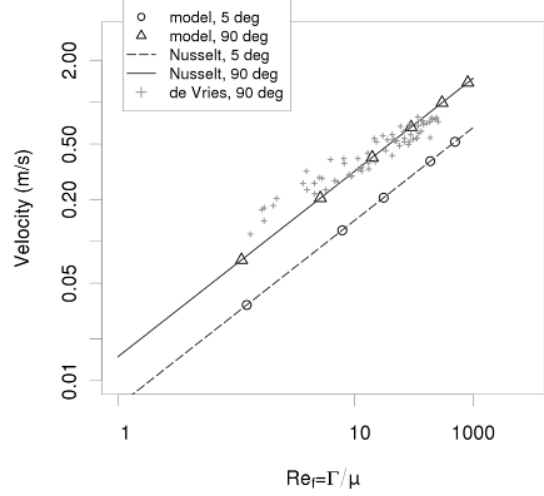

(b)

Fig. 5. Comparisons with Nusselt solution and experimental data [40]: (a) film thickness; (b) velocity.

\section{Rack Storage Water Transport}

The rack-storage, water-transport efficiency test described in Ref. [29] was simulated for three water application rates of 4,12 , and $24 \mathrm{~L} / \mathrm{min} \cdot \mathrm{m}^{2}$ (or $\mathrm{mm} / \mathrm{min}$ ). Three flow rates were applied from 48 nozzles, designed to give uniform coverage. The box arrays used in the tests were a $2 \times 2 \times 3$ arrangement of Class 2 commodity excluding the wood pallets, as shown in Fig. 6a. The boxes measured $1.07 \mathrm{~m}$ on all sides. A uniform grid spacing of $12.7 \mathrm{~mm}$ was used for the surface film model, resulting in 127,000 computational cells on 3 boxes (symmetry boundary conditions were used). A time step size of $1 \mathrm{~ms}$ was used for all simulations. Running the simulations on 16 processors, $220 \mathrm{~s}$ of simulation time was completed in $70 \mathrm{~h}$ of wall-clock time.

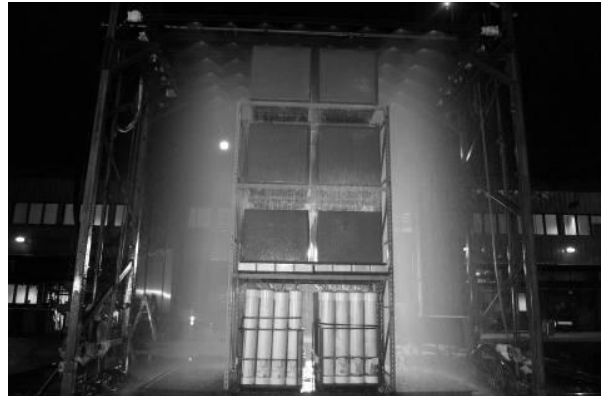

(a)

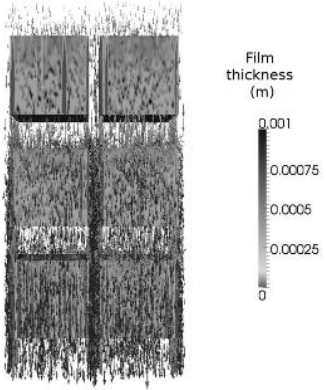

(b)

Fig. 6. Qualitative comparison of experiment and model for high delivered flux of $24 \mathrm{~L} / \mathrm{min} \cdot \mathrm{m}^{2}$.

Model results are shown in Fig. $6 \mathrm{~b}$ for the $24 \mathrm{~L} / \mathrm{min} \cdot \mathrm{m}^{2}$ application rate. In the simulations, the flux applied to the top of the boxes was taken from the test data values for the measured steady-state flow rate at the top tier. Good visual agreement is observed between the wetted area in the experiment and in the simulation. The simulation results show a thick water film on the top of the upper tier, film transport down the sides, and accumulation on the bottom surface with dripping to the next tier. The simulation correctly predicts 
flooding of the box surfaces for this application rate. The simulation predicts a flooded condition over the entire surface, albeit minimal flooding along the box vertical corners.

At the lower flow rates, the water film does not flood the entire surface, but rather forms rivulets. Figure 7 shows qualitative comparisons for the lowest application rate, $4 \mathrm{~L} / \mathrm{min} \cdot \mathrm{m}^{2}$. Rivulets are seen being formed in both the experiment and in the model output. The model utilized a rather coarse mesh for the solution, and as such, the rivulet width is predicted to be larger than that observed in the experiment. However, the model does capture the general trend that at low application rates the surface is only partially wetted while at high application rates the surface is flooded. The lowest flow rate produces thin rivulets that meander down the surface. As the flow rate increases, the rivulets thicken and gain momentum. Finally, for the highest flow rate, the contact-angle force is overcome altogether and the film is continuous.
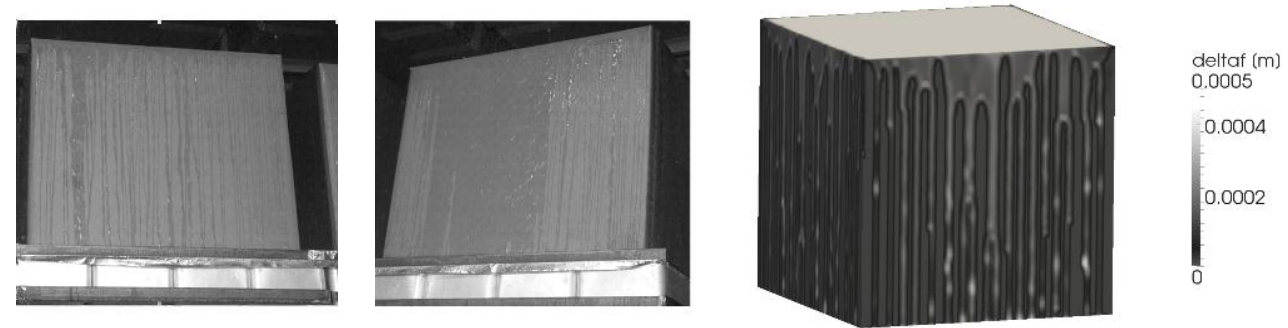

Fig. 7. Qualitative comparisons of experiment and model predictions for film thickness with an applied flux of $4 \mathrm{~L} / \mathrm{min} \cdot \mathrm{m}^{2}$.

A plot of simulated mass flow rate over time for the initial $150 \mathrm{~s}$ is shown in Fig. 8. The mass flow rate represents the sum of the sampled mass flow rate at the bottom edge of the top and bottom tiers. Included in the plot are the measured mass flow rate values from de Vries et al. [29]. The experimental data shows that water is lost as it progresses down the tiers. Experimentally, the tier-to-tier transport results in water loss due to absorption, splashing, evaporation and misalignment of commodities. The transport efficiency generally decreases with increasing water flux and number of tiers, so that up to $25 \%$ of the applied density can be lost by the third tier.

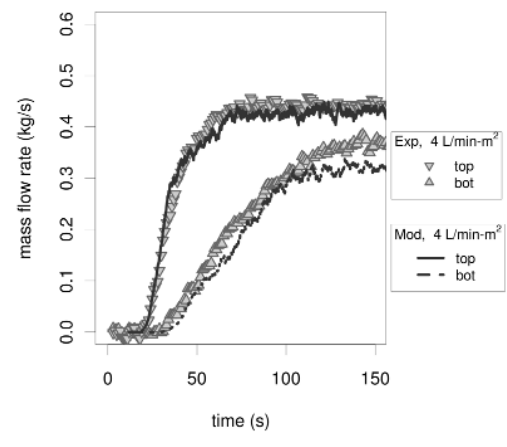

(a)

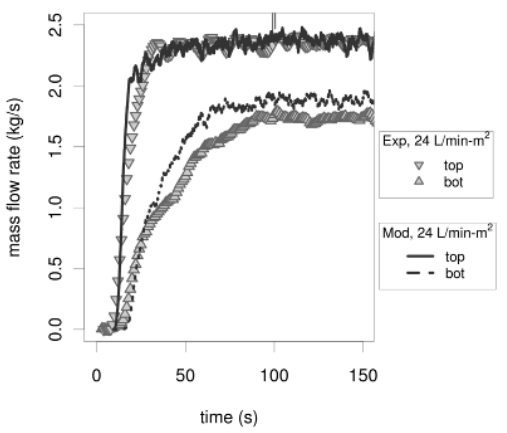

(b)

Fig. 8. Mass flow rates for: (a) low; (b) high water application levels shown with measured flow rate data [29].

The simulations capture the transient mass flow rate curves accurately. The source of mass loss in the model as the water traverses down the tiers is primarily due to splashing. However, experimental observation shows that an additional $\sim 1 \mathrm{~kg}$ of mass gets trapped in each box. Thus, a simple source term has been added to the model to account for the mass loss over time due to water being trapped in the box. The authors believe further improvements in the model predictions can be made by improving the separation model. Currently, the film must progress underneath the box before dripping to the next tier. An improved separation model is needed to simulate accurately flow around sharp corners at high velocities. 


\section{SUMMARY}

The basic approach for the water-film transport model has been clearly outlined, including the transport equations for mass, momentum, and energy. A thin-film assumption was employed to simplify the transport equations to essentially a 2-D surface model. Submodels for relevant source terms related to interfacial transfer and film flow have been formulated, including division of the source terms into surface-normal and surface-tangential terms.

Key features of the development of the water-film transport model include:

- Interaction with the spray model through impingement, splashing, and film separation.

- Incorporation of a contact-angle force, allowing for simulation of partially wetted film flows. Key parameters are the critical film thickness and the contact angle.

- Incorporation of the basic transport model in OpenFOAM along with relevant source terms.

- An extruded mesh approach, allowing easy decoupling from the gas-phase mesh solver, yet provides convenient coupling of inter-phase transport source terms.

Initial validation of the film model was performed. Favorable comparisons were made to the Nusselt solution and to the experimental data for film thickness and velocity for flow over an inclined surface. Additionally, tier-to-tier transport of the model was demonstrated for a $2 \times 2 \times 3$ array of boxes subject to uniform water application. Qualitative visual comparisons show good agreement between the experiment and model for flooding behavior. Comparisons were also made with experimentally measured mass flow rates. The model compares well with steady-state mass flow rate data, and even adequately captures the transient mass flow rate curve. Improved separation treatment is likely needed in the model to help improve the transient behavior of the water film as it progresses down the tiers. Future work will involve coupling of this model with the gas-phase solver in FireFOAM.

Although the discussion here has focused on corrugated cardboard boxes, the model is not limited to this type of surface/geometry. Indeed, the implementation of the model in OpenFOAM allows for simulating liquid flow over any definable surface. Admittedly, improvements to the film separation, mass absorption, and splashing models are likely needed before extending the model to other types of surfaces.

\section{REFERENCES}

[1] Wang, Y., Chatterjee, P., and de Ris, J.L., (2011) Large Eddy Simulation of Fire Plumes, Proceedings of the Combustion Institute, 33(2): 2473-2480, http://dx.doi.org/10.1016/j.proci.2010.07.031

[2] Chatterjee, P., de Ris, J.L., Wang, Y., and Dorofeev, S. B., (2011) A Model for Soot Radiation in Buoyant Diffusion Flames, Proceedings of the Combustion Institute, 33(2):2665-2671, http://dx.doi.org/10.1016/ j.proci.2010.06.112

[3] Chatterjee, P., Krishnamoorthy, N., Wang, Y., de Ris, J.L., and Dorofeev, S.B., "CFD Simulation of Radiative Heat Transfer Between a Buoyant Turbulent Fire and Inert Parallel Panels," Proceedings of the 12th Fire Science and Engineering Conference, INTERFLAM, Nottingham, UK, Jul 5-7, 2010, pp. 777-788.

[4] Krishnamoorthy, N., Chaos, M., Khan, M.M., Chatterjee, P., Wang, Y., and Dorofeev, S.B., "Experimental and Numerical Study of Flame Spread in Parallel Panel Geometry," Sixth International Seminar on Fire and Explosion Hazards, Leeds, UK, April 11-16, 2010.

[5] Krishnamoorthy, N., Chaos, M., Khan, M.M., Chatterjee, P., Wang, Y., and Dorofeev, S.B., "Application of Bench-Scale Material Flammability Data to Model Flame Spread in MediumScale Parallel Panel Test," Proceedings of the $12^{\text {th }}$ Fire Science and Engineering Conference, INTERFLAM, Nottingham, UK, Jul 5-7, 2010, pp. 709-720.

[6] Zhou, X., D'Aniello, S., and Yu, H-Z., "Spray Pattern Measurements of Selected Fire Sprinklers," Proceedings of the 12th Fire Science and Engineering Conference, INTERFLAM, Nottingham, UK, Jul 5-7, 2010, pp. 177-188. 
[7] Hopf, L., (1910) Turbulenz bei einem Flusse, Ann. Physik 337(9): 777-808, http://dx.doi.org/10.1002/andp.19103370905

[8] Nusselt, W., (1916) Die Oberflachenkondensation des Wasserdampfes, Zeitschrift des Vereines Deutscher Ingenieure 60: 541-546 and 569-575.

[9] Nusselt, W., (1923) Heat Transfer in the Trickle Cooler, Zeitschrift des Vereines Deutscher Ingenieure 67: 206-210.

[10] Fulford, G.D., Thomas B., Drew, J.W., Hoopes, J.T.V., and Cokelet, G.R., (ed.) The Flow of Liquids in Thin Films, Academic Press, 1964, p. 151-236.

[11] Tong, A.Y. and Wang, Z.A., (2007) Numerical Method for Capillarity-Dominant Free Surface Flows, Journal of Computational Physics 221: 506-523, http://dx.doi.org/10.1016/j.jcp.2006.06.034

[12] Saha, A.A. and Mitra, S.K., (2009) Effect of Dynamic Contact Angle in a Volume of Fluid (VOF) Model for a Microfluidic Capillary Flow, Journal of Colloid and Interface Science 339: 461-480, http://dx.doi.org/10.1016/j.jcis.2009.07.071

[13] Otto, F., (1998) Lubrication Approximation With Prescribed Non-Zero Contact Angle, Communications in Partial Differential Equations 23: 2077-2164, http://dx.doi.org/10.1080/03605309808821411

[14] Moyle, D.T., Chen, M.S., and Homsy, G.M., (1999) Nonlinear Rivulet Dynamics During Unstable Wetting Flows, International Journal of Multiphase Flow 25: 1243-1262, http://dx.doi.org/10.1016/S0301-9322(99)00062-2

[15] Diez, J.A. and Kondic, L., (2002) Computing Three-Dimensional Thin Film Flows Including Contact Lines, Journal of Computational Physics 183: 274-306, http://dx.doi.org/10.1006/jcph.2002.7197

[16] Frassy, J., Lecot, C., Murariu, M., Delattre, C., and Soucemarianadin, A., "Transient Spreading of Films on Heterogeneous Surfaces," Proceedings of the COMSOL Users Conference, Grenoble, France, Oct 23-24, 2007.

[17] King, A., Cummings, L., Naire, S., and Jensen, O., (2007) Liquid Film Dynamics in Horizontal and Tilted Tubes: Dry Spots and Sliding Drops, Physics of Fluids 19: 042102, http://dx.doi.org/10.1063/1.2714569

[18] Wegener, J.L., Friedrich, M.A., Drallmeier, J.A., and Armaly, B.F., "Experimental Evaluation of a Film Separation Criterion," ICLASS 11th Triennial International Conference on Liquid Atomization and Spray Systems, Vail, USA, Jul 26-30, 2009.

[19] Owen, I. and Ryley, D.J., (1985) The Flow of Thin Liquid Films Around Corners, International Journal of Multiphase Flow 11: 51-62, http://dx.doi.org/10.1016/0301-9322(85)90005-9.

[20] Johnson, M.F.G., Schluter, R.A., Miksis, M.J., and Bankoff, S.G., (1999) Experimental Study of Rivulet Formation on an Inclined Plate by Fluorescent Imaging, Journal of Fluid Mechanics 394: 339-354, http://dx.doi.org/10.1017/S0022112099005765

[21] Semiczek-Szulc, S. and Mikielewicz, J., (1978) Experimental Investigation of Contact Angles of Rivulets Flowing Down a Vertical Solid Surface, International Journal of Heat and Mass Transfer 21: 1625-1625, http://dx.doi.org/10.1016/0017-9310(78)90018-2

[22] Joo, S.W., Davis, S.H., and Bankoff, S.G., (1996) A Mechanism for Rivulet Formation in Heated Falling Films, Journal of Fluid Mechanics 321: 279-298, http://dx.doi.org/10.1017/S0022112096007720

[23] Joo, S.W., Davis, S.H., and Bankoff, S.G., (1993) Two- and Three-Dimensional Instabilities and Rupture of Thin Liquid Films Falling on Heated Inclined Plate, Nuclear Engineering and Design 141: 225-236, http://dx.doi.org/10.1016/0029-5493(93)90103-G 
[24] Trela, M. (1994) A Semi-Theoretical Model of Stability of Vertical Falling Liquid Flms, Chemical Engineering Science 49: 1007-1013, http://dx.doi.org/10.1016/0009-2509(94)80007-3

[25] Chinnov, E.A. and Kabov, O.A., (2004) The Effect of Three-Dimensional Deformations on Local Heat Transfer to a Nonuniformly Heated Falling Film of Liquid, High Temperature 42: 267-277, http://dx.doi.org/10.1023/B:HITE.0000026159.25885.55

[26] Bai, C. and Gosman A.D., "Mathematical Modeling of Wall Films Formed by Impinging Sprays," Society of Automotive Engineers, Imperial College of Science, Technology and Medicine (SAE 960626), 1996.

[27] Stanton, D.W. and Rutland C.J., (1998) Multi-Dimensional Modeling of Thin Liquid Films and Spray-Wall Interactions Resulting from Impinging Sprays, International Journal of Heat and Mass Transfer 41: 3037-3054, http://dx.doi.org/10.1016/S0017-9310(98)00054-4

[28] O'Rourke, P.J. and Amsden A.A., "A Particle Numerical Model for Wall Film Dynamics in PortFuel Injected Engines,” SAE Paper 961961, 1996.

[29] de Vries, J., Xin, Y., and Meredith, K.V., An Experimental Study of Fire Suppression Physics for Sprinkler Protection, Fire Safety Science 10, 2011.(accepted for presentation).

[30] Kabov, O.A., Scheid, B., Sharina, I.A., and Legros, J.C., (2002) Heat Transfer and Rivulet Structures Formation in a Falling Thin Liquid Film Locally Heated, International Journal of Thermal Sciences 41: 664-672, http://dx.doi.org/10.1016/S1290-0729(02)01361-3

[31] Bai, C. Modelling of Spray Impingement Processes, Imperial College of Science, Technology, and Medicine; University of London, 1996.

[32] Bai, C. X., Rusche, H., and Gosman., A.D., (2002) Modelling of gasoline spray impingement, Atom. Sprays, 12: 1-27, http://dx.doi.org/10.1615/AtomizSpr.v12.i123.10.

[33] Zhang, F., Zhao, X., Geng, J., Wu, Y.-T., and Zhang, Z., (2007) A New Insight Into Marangoni Effect in Non-Isothermal Falling Liquid Films, Experimental Thermal and Fluid Science 31: 361365, http://dx.doi.org/10.1016/j.expthermflusci.2006.05.008

[34] Zuber, N. and Staub, F.W., (1966) Stability of Dry Patches Forming in Liquid Films Flowing Over Heated Surfaces, International Journal of Heat and Mass Transfer 9: 897-905, http://dx.doi.org/10.1016/0017-9310(66)90064-0

[35] Zhang, F., Wu, Y.-T., Geng, J., and Zhang Z.-B., (2008) An Investigation of Falling Liquid Films on a Vertical Heated/Cooled Plate, International Journal of Multiphase Flow 34: 13-28, http://dx.doi.org/10.1016/j.ijmultiphaseflow.2007.08.003

[36] Hartley, D.E. and Murgatroyd. W., (1964) Criteria for the Break-Up of Thin Liquid Layers Flowing Isothermally Over Solid Surfaces, International Journal of Heat and Mass Transfer 7: 1003-1015, http://dx.doi.org/10.1016/0017-9310(64)90042-0

[37] Al-Khalil, K.M., Keith, Jr, T.G., and De Witt, K.J., (1991) Hydrodynamic and Thermal Analysis of Rivulet Flow Down a Vertical Solid Surface. International Journal of Numerical Methods for Heat and Fluid Flow 1: 63-76.

[38] Schlichting, H., Boundary Layer Theory, McGraw-Hill, New York, (6 ${ }^{\text {th }}$ ed.), 1968.

[39] Incropera, F.P. and DeWitt D.P., Fundamentals of Heat and Mass Transfer, John Wiley \& Sons, Hoboken, ( $4^{\text {th }}$ ed. $), 1996$.

[40] de Vries, J., D’Aniello S., and Xin Y., "Water Flows on Vertical Surface and around Corners of Corrugated Cardboards for Sprinkler Protection of Rack Storage," Proceedings of the $12^{\text {th }}$ Fire Science and Engineering Conference, INTERFLAM, Nottingham, UK, Jul 5-7, 2010, pp. 143152. 